\title{
Analisis Sifat Fisik Semen Organik Terbuat dari Bahan Limbah Daur Ulang
}

\author{
* Muhammad Syarif ${ }^{1}$ \\ ${ }^{1}$ Jurusan Arsitektur, Fakultas Teknik, Universitas Muhammadiyah, Makassar, Indonesia \\ muhsyarif00@gmail.com \\ *Alamat korespondensi, Masuk: 01 Jan. 2019, Direvisi: 15 Jan. 2019, Diterima: 05 Feb. 2019
}

\begin{abstract}
ABSTRAK: Penelitian ini bertujuan sebagai penyelamatan lingkungan dan penemuan bahan bangunan alternatif terbaru. Dalam penelitian ini, telah menghasilkan semen organik yang merupakan semen alternatif terbaru selain dari semen portland yang dibuat melalui sistem daur ulang limbah organik, fly ash, bottom ash, dan substitusi tanah mediteran. Metode yang digunakan dalam penelitian ini adalah pengujian laboratorium. Pengujian digunakan untuk menentukan unsur senyawa kimia pada masingmasing bahan utama semen organik. Dari hasil analisis senyawa kimia semen organik melalui metode pengujian laboratorium, telah ditemukan indikasi yang mirip dengan senyawa kimia semen portland dalam bentuk: $\mathrm{CaO} ; 65,36 \%$, SiO2 18,84\%, Al2O3 6,33\%, Fe2O3 2,29\%, SO3 3,64\%, MgO 1,35\%, C3S 66, 72\%, C2S 3,98\%, C3A 12,9\%, dan C4Af 6,97\%. Bleeding beton semen organik untuk $1 \mathrm{~m}^{3}$ adalah 23,88 ml/ $\mathrm{cm}^{2}$, lebih rendah dari bleeding beton semen portland yang mencapai $31,83 \mathrm{ml} / \mathrm{cm}^{2}$. Kadar udara beton semen organik dalam $1 \mathrm{~m}^{3}$ adalah 2,2\%, sedang kadar udara beton semen portland mencapai 1,9\%. Berat unit semen organik diperoleh $1.200 \mathrm{~kg} / \mathrm{m}^{3}$, lebih ringan dari semen portland yang mencapai $1.250 \mathrm{~kg} / \mathrm{m}^{3}$.
\end{abstract}

Kata kunci: Tanah mediteran, Semen organik, Limbah organik, Semen portland.

\begin{abstract}
This research aims to the environmental saving process and the discovery of the latest alternative building materials. In the research, the researchers have produced an organic cement that is the latest alternative cement aside from portland cement which is made through organic waste recycling system, fly ash, bottom ash, and substitution of mediteran soil and clay. The method used in this research is laboratory testing. The testing is used to determine the element of chemical compound on each organic cement's main ingredients. From the analysis result of chemical compound of organic cement through laboratory testing method, it has been found indication that similar to chemical compound of portland cement in the form of: $\mathrm{CaO} ; 65.36 \%$, SiO2 18.84\%, A12O3 6.33\%, Fe2O3 2.29\%, SO3 3.64\%, MgO 1.35\%, C3S $66,72 \%$, C2S 3.98\%, C3A $12.9 \%$, and C4Af $6.97 \%$. The bleeding of $1 \mathrm{~m}^{3}$ organic cement concrete is $23,88 \mathrm{ml} / \mathrm{cm}^{2}$, which is lower than the bleeding of portland cement concrete that reaches $31,83 \mathrm{ml} / \mathrm{cm}^{2}$. The air content of $1 \mathrm{~m}^{3}$ organic cement concrete is $2,2 \%$, which is lower than the air content of portland cement concrete that reaches $1,9 \%$. The obtained alternative cement solid weight is $1200 \mathrm{~kg} / \mathrm{m}^{3} \mathrm{more}$ light from portland cement which reaches $1250 \mathrm{~kg} / \mathrm{m}^{3}$.
\end{abstract}

Keywords: Mediteran soil, organic cement, organic waste, portland cement

\section{PENDAHULUAN}

Penekanan hasil penelitian berorientasi pada pemanfaatan daur ulang limbah pada bahan yang tidak berkontribusi banyak dalam kehidupan masyarakat sejauh ini. Semen organik adalah semen alternatif terbaru selain dari semen portland yang dibuat melalui sistem daur ulang limbah organik dan substitusi tanah mediteran [1].

Semakin meningkatnya pertumbuhan penduduk dunia maka bahan bangunan perlu juga diatasi dengan melakukan penelitian melalui pemanfaatan limbah daur ulang untuk mendapatkan bahan bangunan yang bisa menjadi bahan alternatif [2]. Saat ini, masalah sampah adalah masalah yang dihadapi di seluruh dunia. Tingginya volume limbah memiliki dampak negatif terhadap lingkungan. Penanganan pengelolaan limbah perlu dilakukan untuk memperkecil dampak negatif yang dapat dihasilkan. Masalah sampah sepertinya bukan hal yang sederhana, karena selama ada kehidupan manusia maka masalahnya akan selalu muncul. 
Pengelolaan sampah kota di Indonesia menjadi masalah nyata seiring dengan meningkatnya pertumbuhan populasi yang berdampak pada meningkatnya jumlah sampah dan terjadinya masalah degradasi estetika di sekitar TPA yang berpotensi menyebabkan konflik sosial dengan masyarakat sekitar [3].

Sampah adalah barang atau benda yang tidak memiliki nilai manfaat dan menciptakan kesan negatif yang menyebabkan sampah tersebut dipandang sebagai benda yang harus dibuang dari halaman rumah dengan cara apa pun [4]. Pertumbuhan volume sampah yang tinggi seringkali bertepatan dengan tingginya tingkat pertumbuhan populasi. Oleh karena itu, masalah limbah saat ini dapat dikatakan sebagai masalah dunia yang dihadapi. Selain itu, dengan penanganan yang baik dan pengelolaan limbah yang baik, penghematan lingkungan telah dilakukan. Penanganan limbah organik melalui proses pembakaran dengan tungku pada suhu $700 \mathrm{o} \mathrm{C}$ akan menjadi abu yang mengandung unsur $69,7 \% \mathrm{CaCO} 3,12,1 \% \mathrm{KCl} ; 3 \%$ $\mathrm{SiO} 2,8,1 \% \mathrm{Fe}$ dan 3\% A12, sedangkan abu kerang mengandung $100 \% \mathrm{CaCO} 3$ [5].

Seiring dengan pertumbuhan ekonomi, produksi sampah per kapita akan terus meningkat sehingga prediksi pada tahun 2030 akan mencapai $1,2 \mathrm{~kg} / \mathrm{kapita} /$ hari untuk daerah perkotaan dan 0,55 $\mathrm{kg}$ /orang/hari untuk daerah pedesaan.

Di Indonesia sampah organik memiliki persentase tertinggi dibanding sampah anorganik. Proporsi limbah organik adalah antara $34-70 \%$, 20$30 \%$ lebih tinggi daripada kebanyakan negara di Eropa [6].

Tanah Mediteran adalah tanah yang terbentuk dari pelapukan batuan sedimen dan batuan kapur. Jenis tanah ini mengandung sejumlah besar karbonat dan senyawa lain dari besi, air, aluminium, dan beberapa bahan organik lainnya [7].

Tanah liat akan mengalami perubahan kimia ketika tanah liat dibakar, baik lempung primer dan sekunder. Perubahan pertama yang terjadi pada tanah liat primer dan sekunder ketika dibakar, adalah hilangnya air bebas, terutama untuk tanah liat sekunder akan diikuti oleh pembakaran bahan organik lainnya, seperti humus, daun, dan ranting yang terkandung dalam tanah liat. Pada perubahan selanjutnya, kandungan air kimia akan hilang. Tanah liat primer dan sekunder mengandung silika bebas dalam bentuk pasir, kuarsa, batu api, dan kristal. Silika adalah subjek untuk mengubah bentuk dan volume tanah liat pada suhu tertentu. Beberapa perubahan diperbaiki (konversi) dan lainnya dapat dibalik. Tanah liat yang melalui proses pembakaran dengan suhu melebihi $600^{\circ} \mathrm{C}$ akan berubah menjadi mineral padat, keras dan permanen [8].

Meningkatnya permintaan akan perumahan dan infrastruktur secara otomatis menuntut kebutuhan akan bahan bangunan yang terus meningkat. Meningkatnya kebutuhan bahan bangunan harus diatasi dengan penggunaan dan penemuan bahan bangunan yang dapat memberikan alternatif. Peningkatan pertumbuhan semen sampai saat ini masih dipengaruhi oleh pembangunan yang cukup tinggi yang dilakukan oleh sektor swasta karena tingginya permintaan perumahan bagi masyarakat [9].

Semen yang mengandung unsur mineral sebagai pengganti semen portland dikenal sebagai semen komposit, semen campuran atau semen alternatif. Komponen mineral yang ditambahkan disebut mineral tambahan yang reaktif dan berkontribusi pada proses hidrasi. Semen yang mengandung unsur mineral sebagai pengganti semen portland dikenal sebagai semen komposit, campuran semen atau semen alternatif. Komponen mineral yang ditambahkan disebut mineral tambahan yang reaktif dan berkontribusi pada proses hidrasi. Penggunaan fly ash jenuh adalah salah satu cara untuk mengurangi proses hidrasi semen dalam beton [10].

Limbah batu bara dalam bentuk fly ash yang dihasilkan dari hasil pembuangan pembakaran pembangkit listrik umumnya masih terabaikan untuk digunakan di sebagian besar negara [11].

Semakin besar persentase hidrasi fly ash. maka waktu pengikatan awal dan akhir lebih lambat. Senyawa C3S, C2S, C3A dan C4AF akan bereaksi dengan air, dimulai dengan senyawa C3A bereaksi dengan unsur-unsur utama yang ada dalam abu terbang silika dan alumina sehingga rantai reaksi hidrasi akan sangat lama yang pada akhirnya akan meningkatkan waktu pengikatan beton. Semakin besar kandungan fly ash sebagai pengganti jumlah semen dalam campuran beton, senyawa $\mathrm{C} 3 \mathrm{~S}, \mathrm{C} 2 \mathrm{~S}$, $\mathrm{C} 3 \mathrm{~A}$ dan $\mathrm{C} 4 \mathrm{AF}$ akan berkurang karena hal ini akan mengakibatkan berkurangnya panas hidrasi. Panas hidrasi yang berkurang akan memperlambat reaksi sehingga akan memperlambat waktu pengikatan [12].

Butiran fly ash yang terbaik digunakan adalah yang lolos saringan 200 mesh yang mengandung $\mathrm{SiO} 2, \mathrm{~A} 12 \mathrm{O} 3, \mathrm{P} 2 \mathrm{O} 5$, dan $\mathrm{Fe} 2 \mathrm{O} 3$. Kandungan silika yang cukup tinggi memungkinkan abu batubara memenuhi kriteria sebagai bahan yang memiliki sifat semen / pozzolan [13]. Penggunaan fly ash menciptakan pengurangan emisi polusi udara yang berdampak negatif terhadap perekonomian, telah 
diamati bahwa 0,9 ton $\mathrm{CO} 2$ dihasilkan per ton produksi semen. Dengan demikian penggunaan fly ash memungkinkan untuk mengurangi emisi $\mathrm{CO} 2$ atmosfer sebagai bentuk rekayasa ramah lingkungan [14]. Efek penambahan sejumlah abu terbang akan meningkatkan kekuatan beton [15].

Pengembangan penggunaan sumber-sumber arletranif untuk pembuatan semen juga telah dikembangkan oleh Jepang yang memproduksi semen ramah lingkungan yang terbuat dari abu limbah kota melalui pembakaran sebagai pengganti beberapa bahan baku utama yang mengandung 50\% bahan baku semen seperti limbah lumpur [16].

Untuk membuat Klinker Eco-Semen CSA maka bahan baku awal yang tepat perlu dibakar pada suhu maksimum 1200-1300 ${ }^{\circ}$ C. Penggunaan kembali bahan limbah dalam bentuk phosphogypsum akan mengurangi suhu dan waktu proses pembakaran. Pembuatan semen skala besar dapat dilakukan dalam rotary kiln konvensional yang digunakan untuk semen portland dan memproduksi mineralisasi semen kimia $\mathrm{C}=\mathrm{CaO}, \mathrm{A}$ $=\mathrm{A} 12 \mathrm{O} 3, \mathrm{~S}=\mathrm{SiO} 2, \mathrm{~s}=\mathrm{SO} 3, \mathrm{~F}=\mathrm{Fe} 2 \mathrm{O} 3, \mathrm{M}=\mathrm{MgO}$. Ye'elimite $4 \mathrm{CaO} \cdot 3 \mathrm{Al} 2 \mathrm{O} 3 \cdot \mathrm{SO} 3$ yaitu $\mathrm{C} 4 \mathrm{~A} 3 \mathrm{~s}$ [17].

\section{METODE DAN INSTRUMEN PENELITIAN}

Dalam penelitian eksperimental ini, pengujian dilakukan pada konsentrat semen organik dan dilakukan pada konsentrat bahan baku utama pembentukan semen organik melalui pengujian laboratorium kimia. Pengujian digunakan untuk menentukan elemen kimia serta strukturnya untuk mengetahui sifat fisiknya. Pengujian analisis pada aboratorium kimia adalah senyawa $\mathrm{CaO}, \mathrm{SiO} 2$, $\mathrm{Al} 2 \mathrm{O} 3, \mathrm{Fe} 2 \mathrm{O} 3, \mathrm{SO} 3, \mathrm{MgO}$, Loi, Na2O, K2O, C3S, C2S, C3A dan C4Af. Metode pengujian elemen kimia mengacu pada ASTM C-114-07 [18]. Referensi tersebut adalah referensi normatif yang dianggap sangat relevan dalam proses pengujian senyawa kimia seme

Metode pengujian sifat fisik dilakukan di laboratorium struktur dan bahan yang meliputi bleeding, kadar udara, dan pengujian berat unit pada beton semen organik dan beton semen portland. Untuk melihat kelayakan semen organik, sampel uji juga mencakup pengujian senyawa kimia untuk tanah mediteran, limbah organik berupa limbah rumah tangga, fly ash, bottom ash dan tanah liat. Sampel pembanding yang digunakan dalam pengujian eksperimental ini adalah semen Portland.

\section{HASIL DAN PEMBAHASAN}

Semen organik dibentuk dengan memanfaatkan substitusi bahan alami berupa tanah mediteran dengan pengelolaan bersama mendaur ulang limbah organik dalam bentuk limbah rumah tangga, fly ash, bottom ash dan tanah liat. Setelah semua bahan baku diproses, dilakukan pengujian terhadap unsur-unsur kimia yang dimiliki pada masing-masing bahan baku tersebut. Kemudian, setelah pencampuran bahan baku untuk membentuk klinkernisasi, pengelolaan bahan dilakukan sampai membentuk konsentrat semen organik. Selanjutnya, konsentrat semen organik ini juga diproses dengan pengujian elemen kimia. Untuk melihat kelayakan konsentrat semen organik sebagai semen alternatif, pengembangan penelitian yang dilakukan oleh peneliti adalah menganalisis konsentrat semen organik pada pemeriksaan sifat fisik berupa bleeding, kadar udara, dan pengujian berat unit.

Hasil pengujian kuat tekan silinder beton yang menggunakan semen portland pada metode water curing menghasilkan 22,37 $\mathrm{MPa}$ sedang untuk metode dry curing menghasilkan 19,71 MPa. Untuk beton semen organik pada metode perawatan water curing menghasilkan $8,52 \mathrm{MPa}$ sedang untuk metode dry curing menghasilkan 14,52 Mpa [19].

\section{Senyawa Kimia dan Karakteristik Semen Organik}

Pengujian elemen kimia dimaksudkan untuk menentukan kandungan senyawa kimia dengan membandingkan senyawa kimia yang terkandung dalam semen portland. Konsentrat semen organik dibentuk dengan meman faatkan substitusi bahan alami dalam bentuk tanah mediteran dan daur ulang limbah organik yang merupakan limbah rumah tangga, fly ash, bottom ash dan tanah liat. Tabel 1 menunjukkan hasil pengujian unsur kimia konsentrat semen organik. dan tabel 2 menunjukkan hasil pengujian unsur utama semen organik

Tabel 1. Elemen kimia konsentrat semen organik dibandingkan dengan semen portland berdasarkan ASTM C114-07

\begin{tabular}{lcll}
\hline & & & Results \\
\cline { 3 - 4 } Parameter & Unit & $\begin{array}{l}\text { Organik } \\
\text { Semen }\end{array}$ & $\begin{array}{l}\text { Portland } \\
\text { cement } \\
\text { (ASTM - } \\
\text { C 114) }\end{array}$ \\
\hline $\mathrm{C}_{3} \mathrm{~S}$ & $\%$ & 69,90 & $50-70$ \\
$\mathrm{C}_{2} \mathrm{~S}$ & $\%$ & 7,30 & $15-30$ \\
$\mathrm{C}_{3} \mathrm{~A}$ & $\%$ & 10,3 & $5-10$ \\
$\mathrm{C}_{4} \mathrm{AF}$ & $\%$ & 3,1 & $5-15$ \\
$\mathrm{SiO}_{2}$ & $\%$ & 21,29 & 20,6 \\
$\mathrm{Al}_{2} \mathrm{O}_{3}$ & $\%$ & 7,86 & 5,07 \\
\hline
\end{tabular}




\begin{tabular}{llll}
\hline $\mathrm{Fe}_{2} \mathrm{O}_{3}$ & $\%$ & 4,40 & 2,9 \\
$\mathrm{CaO}$ & & 68,43 & 63,9 \\
$\mathrm{SO}_{3}$ & $\%$ & 3,20 & 2,53 \\
$\mathrm{Na}_{2} \mathrm{O}+\mathrm{K}_{2} \mathrm{O}$ & $\%$ & 1,58 & 0,88 \\
$\mathrm{MgO}$ & $\%$ & 4,80 & 1,53 \\
\hline
\end{tabular}

Tabel 2. Unsur kimia adalah bahan utama konsentrat semen organik

\begin{tabular}{|c|c|c|c|c|c|c|}
\hline \multirow{2}{*}{$\begin{array}{l}\text { Param } \\
\text { eter }\end{array}$} & \multirow{2}{*}{$\begin{array}{l}\mathrm{U} \\
\mathrm{n} \\
\mathrm{i} \\
\mathrm{t}\end{array}$} & \multicolumn{5}{|c|}{ Hasil } \\
\hline & & $\begin{array}{l}\text { Sampah } \\
\text { Orgaik }\end{array}$ & $\begin{array}{l}\text { Tanah } \\
\text { Mediteran }\end{array}$ & $\begin{array}{l}\text { Tanah } \\
\text { Liat }\end{array}$ & $\begin{array}{l}\text { Fly } \\
\text { Ash }\end{array}$ & $\begin{array}{c}\text { Bottom } \\
\text { Ash }\end{array}$ \\
\hline $\mathrm{SiO}_{2}$ & $\%$ & 46,65 & 23,68 & 30,63 & 22,14 & 15,20 \\
\hline $\mathrm{Al}_{2} \mathrm{O}_{3}$ & $\%$ & 2,28 & 0,44 & 3,41 & 3,84 & 2,99 \\
\hline $\mathrm{Fe}_{2} \mathrm{O}_{3}$ & $\%$ & 0,18 & 0,15 & 0,20 & 0,20 & 0,20 \\
\hline $\mathrm{CaO}$ & $\%$ & 11,09 & 19,35 & 0,51 & 6,87 & 1,41 \\
\hline $\mathrm{SO}_{3}$ & $\%$ & 1,01 & 1,66 & 0,01 & 0,89 & 0,15 \\
\hline $\mathrm{Na}_{2} \mathrm{O}$ & $\%$ & 2,24 & 0,01 & 0,23 & 0,37 & 1,03 \\
\hline $\mathrm{K}_{2} \mathrm{O}$ & $\%$ & 11,98 & 0,09 & 0,02 & 0,58 & 0,17 \\
\hline $\mathrm{MgO}$ & $\%$ & 0,02 & 0,018 & 0,36 & 0,03 & 0,02 \\
\hline
\end{tabular}

Gambar 1 menunjukkan proses pembakaran bahan utama semen organik. Pembakaran bahan baku dilakukan dalam mesin pembakaran yang dapat menahan panas hingga 1800 o C. Kontrol suhu pembakaran dengan menggunakan alat termometer TI-1500 infra red sanfix. Pemeriksaan senyawa kimia dilakukan di laboratorium kimia Fakultas Matematika dan Ilmu Pengetahuan Alam Universitas Hasanuddin dan untuk mengetahui sifat fisiknya, dilakukan di laboratorium bahan, struktur dan konstruksi Fakultas Teknik Arsitektur Universitas Hasanuddin.
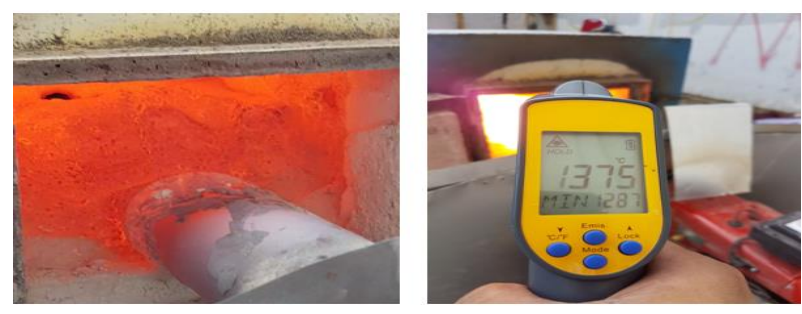

Gambar 1. Proses pembakaran bahan utama semen organik

Untuk membentuk konsentrat semen organik, semua bahan utama dibakar hingga suhu 1400o C. Setelah semua bahan dibakar selama 4 jam, pendinginan dan penyempurnaan dilakukan. Bahan berbentuk konsentrat kemudian menjalani pengujian senyawa kimia untuk melihat pendekatan kelayakan elemen kimia terhadap elemen kimia semen portland. Uji sifat fisik dimaksudkan untuk melihat kelayakan fisik semen organik dalam bentuk kehalusan, dan kepadatan.

Gambar 2 di bawah ini menunjukkan bahan baku semen organik sebelum proses manajemen menjadi konsentrat semen organik.

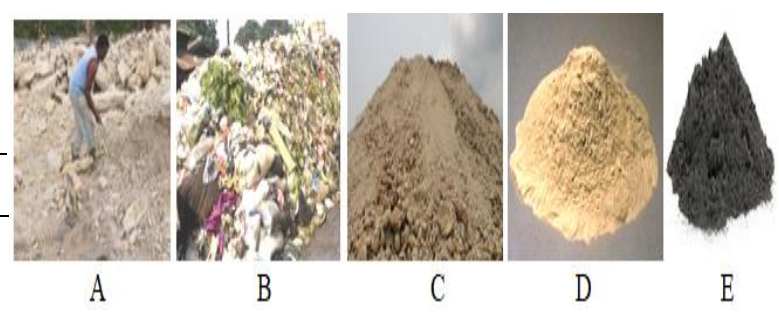

Gambar 2. Tanah Mediteran (A), Limbah rumah tangga (B), Clay (C), Fly ash (D), Bottom Ash (E).

\section{Bleeding dan Kadar Udara Semen Organik}

Jumlah air bleeding untuk beton semen organik dengan berat beton silinder $3,33 \mathrm{~kg}$ sebesar 0,04 $\mathrm{ml} / \mathrm{cm}^{2}$ sehingga prediksi pendarahan air untuk beton $1 \mathrm{~m}^{3}$ dengan semen organik adalah 23,88 $\mathrm{ml} / \mathrm{cm}^{2}$. Sedang untuk beton yang menggunakan semen portland dengan berat beton silinder $3,36 \mathrm{~kg}$ memiliki nilai air bleeding sebesar $0,05 \mathrm{ml} / \mathrm{cm}^{2}$ dengan prediksi bleeding untuk $1 \mathrm{~m}^{3}$ beton semen portland adalah $31,83 \mathrm{ml} / \mathrm{cm}^{2}$.

Gambar 3 berikut ini menunjukkan proses pengukuran air bleeding pada beton semen organik.

Pengujian volume air bleeding silinder beton dihitung dengan referensi berdasarkan ASTM C $232-99[20]$.
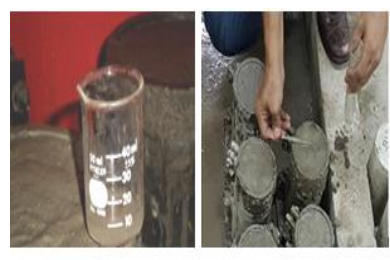

A

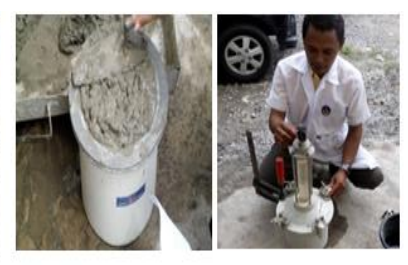

B
Gambar 3. Proses pengukuran pendarahan (A), proses pengukuran konten udara (B)

\section{Berat Unit}

Berat beton segar menggunakan semen organik adalah $2081 \mathrm{~kg} / \mathrm{m}^{3}$ dan berat beton keringnya adalah $2032 \mathrm{~kg} / \mathrm{m}^{3}$, sedangkan berat beton segar dengan menggunakan semen portland adalah 2525 $\mathrm{kg} / \mathrm{m}^{3}$ kemudian berat beton keringnya adalah $2405 \mathrm{~kg} / \mathrm{m}^{3}$. Gambar 4 menunjukkan silinder beton yang terbuat dari semen organik dan konsentrat semen portland. Pada gambar tersebut juga menunjukkan proses pengukuran suhu, berat 
spesimen, dan kondisi beton silinder yang telah diuji tarik.

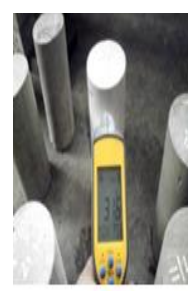

A

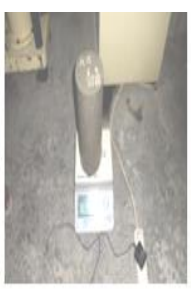

B

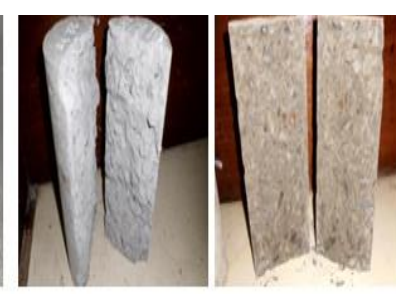

D
Gambar 4. Pengukuran temperatur beton silinder dengan semen organik (A), Pengukuran berat beton silinder dengan semen organik (B), silinder beton dengan semen organik hasil uji tarik (C), silinder beton dengan semen portland hasil uji tarik (D)

\section{KESIMPULAN DAN SARAN}

Dari hasil pengujian sifat kimia dan sifat fisik konsentrat semen organik, telah diperoleh indikasi yang mirip dengan sifat senyawa kimia semen portland yang dalam hal ini digunakan sebagai sampel pembanding. Dalam meningkatkan kualitas semen organik, dipandang perlu untuk melakukan penelitian eksperimental lanjutan. Dalam desain campuran beton yang sama meskipun uji kompresi beton dengan semen organik masih lebih rendah dari beton yang menggunakan semen portland, tetapi semen organik ini dapat digunakan untuk konstruksi ringan

Adapun hasil pengujian sifat fisis yang dimiliki semen organik berdasarkan kajian empiris dinyatakan telah mendekati acuan normatif pada Standar Nasional Indonesia (SNI) dan ASTM

\section{DAFTAR PUSTAKA}

[1] Muhammad S (2017) Karakteristik Sampah Organik dan Tanah Mediteran Menjadi Semen Organik. Konferensi Nasional Teknik Sipil; 26-27 Oktober; Universitas Tarumanagara Jakarta. hal. 23-29.

[2] Syarif M, Tjaronge MW (2018) Characteristic of compressive and tensile strength using the organic cement compare with portland cement. Case Studies in Construction Materials Vol. 9.

[3] Mahyudin RP (2017) Kajian Permasalahan Pengelolaan Sampah dan Dampak Lingkungan di TPA (Tempat Pemrosesan Akhir). Jurnal Teknik Lingungan Vol. 3, No. 1.

[4] Widiarti IW (2012) Pengelolaan sampah berbasis "Zero Waste" skala rumah tangga secara mandiri. Jurnal Sains dan Teknologi Lingkungan Vol. 4, No. 2.

[5] Syafnijal FA, Sawitri D (2013) Studi Eksperimental Pembuatan Ekosemen dari Abu Sampah dan Cangkang Kerang sebagai Bahan Alternatif Pengganti Semen. Jurnal Teknik ITS Vol. 2, No. 2: hal. D162-D165.

[6] Damanhuri E (2010) Indonesia Climate Change Sectoral Roadmape (ICCSR) Sektor Limbah. Indonesia Climate Change Sectoral Roadmape (ICCSR) Sektor Limbah. https://www.bappenas. go.id/files/8913/4986/4554/roadmap-perubahan-iklim-sektor-limbah, Access 17 Feb 2011.

[7] Maulana A (2016) Fungsi Tanah Mediteran Bagi Kehidupan. Fungsi Tanah Mediteran Bagi Kehidupan. http://www.majalahbatu. com/2016/11/fungsi-tanah-mediteran-bagi-kehidupan.html, Access 8 November 2016.

[8] Dwijaya FA, Agoes S (2014) Kajian Bahan Dasar (Lempung) Terhadap Karakteristik Mekanik Batu Bata Yang Dihasilkan Dan Kesesuaian Fungsi Berdasarkan Diagram Winkler. Jurnal Mahasiswa Jurusan Teknik Sipil Vol. 1, No. 3: hal. pp. 936-944.

[9] Nur RR, Hartanti FD, Sutikno JP (2016) Studi Awal Desain Pabrik Semen Portland dengan Waste Paper Sludge Ash sebagai Bahan Baku Alternatif. Jurnal Teknik ITS Vol. 4, No. 2: hal. F164-F168.

[10] Sampebulu V, Sciences T (2012) Influence of high temperatures on the workability of fresh ready-mixed concrete. Journal of Engineering Vol. 44, No. 1: hal. 21-32.

[11] Sampebulu V (2012) Increase on strengths of hot weather concrete by self-curing of wet porous aggregate. Civil Engineering Dimension Vol. 14, No. 2: hal. 92-99.

[12] Sebayang S, Widyawati R, Habibie M (2012) Pengaruh Abu Terbang Terhadap Sifat-Sifat Mekanik Beton Alir Ringan Alwa. Jurnal Teknik Sipil Vol. 3, No. 1.

[13] Tumingan T, Tjaronge M, Sampebulu V, et al. (2016) Penyerapan dan Porositas pada Beton Menggunakan Bahan Pond Ash Sebagai Pengganti Pasir. Jurnal Poli-Teknologi Vol. 15, No. 1.

[14] Garg C, Jain A, technology (2014) Green concrete: Efficient \& eco-friendly construction materials. International journal of research in engineering Vol. 2, No. 2: hal. 259-264.

[15] Marthinus AP, Sumajouw MD, Windah RS (2015) Pengaruh penambahan abu terbang (Fly Ash) terhadap kuat tarik belah beton. Jurnal Sipil Statik Vol. 3, No. 11.

[16] Shunsuke H (2011) Eco-Cement and Eco-Concrete Environmentally Compatible Cement and Concrete Technology. COE Workshop on Material Science in 21st Century for the Construction Industry Durability, Repair and Recycling of Concrete Structures; 5 Augst; Iwata University.

[17] Ukrainczyk N, Frankoviæ Mihelj N, Šipušić J (2013) Calcium sulfoaluminate eco-cement from industrial waste. Chemical biochemical engineering quarterly Vol. 27, No. 1: hal. 83-93. 
[18] American Society for Testing and Material (ASTM) (2007) Designation C 114-07, "Standard Test Methods For of Chemical Analysis of Hydraulic-Cement; P 1-32 CEA, editor. Published August 2007.

[19] Syarif M (2018) Analisis Kuat Tekan Kuat Tarik dan Sifat Fisis Semen Organik Terbuat dari Bahan Limbah Daur Ulang. LINEARS: Jurnal Teknik Arsitektur Vol. 1, No. 2: hal. 85-90.

[20] American Society for Testing and Material (ASTM) (1999) Designation C 232-99 Standard Test Methods For Bleeding Of Concrete Current Anual Book of ASTM Standards, Vol 04.02.

(C) 2019 the Author(s), licensee Jurnal LINEARS. This is an open access article distributed under the terms of the Creative Commons Attribution License

(http://creativecommons.org/licenses/by/4.0) 